\title{
A Comparative Study of Physical Education Ideology between Dewey and TaoXingzhi
}

\author{
Ping Yan ${ }^{1,}$, Yueming Duan ${ }^{2, b}$, \\ ${ }^{1}$ Department of Physical Education in Southwest Petroleum University, Chengdu, 610500, China \\ ${ }^{2}$ Department of Physical Education in Southwest Petroleum University, Chengdu, 610500, China \\ aemail: 381202464@qq.com, bemail:61357829@qq.com
}

Keywords: Dewey, Tao Xingzhi, Sports Thought, Contrast

\begin{abstract}
Dewey and Tao Xingzhi are famous educators and their physical education thoughts are embodied in their education system. The analysis indicates that Dewey's ideas of physical education include Sports Power, Children's Games, Skill Learning, etc., while those of Tao Xingzhi include Health First, Lifetime Sports, Little Man Teaching, etc. A comparative study shows that there are both commonness and differences between them, which has an instructive significance for the development of school sports education in China.
\end{abstract}

\section{A preliminary study of physical education thought of Dewey and Tao Xingzhi}

Documents searching and sorting of sports-related literature indicate that in a fair amount of books such as Chinese Modern School Sports History, Dewey’s sports ideology which are contained in his education thoughts are mentioned, which confirms the influence of Dewey on the development of physical education in China. Scholars have a positive attitude to this kind of influence. Shao Weide et al summarized the physical education thoughts of Dewey from four aspects and believed that Game for Children is the core concept with pragmatism as the basic theory and children instinct and experience as the base. ${ }^{[1]}$ The current researches mainly focus on the enlightenment and significance of Dewey's sports ideology and the corresponding reviews. And there are only seven articles and two of them were published in core journals from 1915 to now.

Literature on Tao Xingzhi and sports mainly focuses on three aspects, his sports ideology, evaluation and significance. Studies on his sports ideology are centered on "health first", "the equal stress on morality, intelligence and physique”, "Sports connotation”. Some scholars mentioned that when the Chongqing Beipei Yucai School was founded in 1939, Tao Xingzhi blended his sports ideology into the "healthy education" and put the health of students and teachers in the first place and proposed the concept that every should exercise appropriately. ${ }^{[2]}$ Many scholars believe that sports ideology is an important part of his education theory. In recent years, the concept of "Health First", "Lifetime Sports" and some other education thoughts in China have a high consistency with Tao's ideology, which has great influence on the Physical Education evaluation system reform of in colleges and universities. ${ }^{[3]}$ Since 1915 , there have been 35 related articles and 10 of them were published in core journals, and researches are relatively intensive.

\section{Physical Education ideas of Dewey and Tao Xingzhi}

Physical Education Ideas of Dewey. (1) Sports power. Dewey proposed that body motion plays an important role in promoting the spirit and vitality of people, and advocated the sports games, for he believed that game not only benefits the body, but also plays a positive role in cultivating our thoughts and habit. He once said that because the Greeks regarded games as a way to exercise and maintain a healthy mind, they are strong and energetic. ${ }^{[4]}$ John Dewey pointed out in a speech in China that we should build public playgrounds and associated facilities, which is conducive to improving national physique and physical habits of Chinese people and plays a great role in the status enhancement of a country.

(2) Game for children. In Dewey’s ideology, "game” refers to all the sports activities enabling a 
vast majority of people to be involved in. Dewey once cited a visual example: some people take exercise whenever they get a chance, while others do not take exercise. After 10 or 20 years, they have great difference mentally and physically, that is, they have different attitude toward the world. People in the first group have rich thoughts and are more energetic, while people in the second group look on things indifferently. ${ }^{[4]}$ Dewey advocated to play games with free attitude and believed that this kind of attitude is more important than the game itself. Meanwhile, he also proposed to convert the attitude toward game into the work attitude which will make children get more profound experience in the game. ${ }^{[5]}$

(3) Skill learning. Dewey believed that the substance of education is to cultivate a habit which is derived from the control the action ---- a skill and ability. ${ }^{[4]}$ To cultivate movement skills requires three stages: the first is the action control, it is necessary to control our own behavior and thoughts; ${ }^{[4]}$ the second is the order movement; the third is the interest in action, thus we can show an interest in new things when we can master them. ${ }^{[4]}$ Skilled people could organize things more rationally and what we do currently is preparing and laying a foundation for the next step.

(4) Experience teaching. Dewey advocated "learning through doing” and he believed that a good way to inspire children is to do. He said Chinese children just stand aside quietly and watch people do it." ${ }^{[4]}$ For example, he cited an example that some students learnt swimming in a school and were required to practice swimming strokes repeatedly on the bank rather than swim in water. When someone asked one student what will happen if he falls into the water, he answered "sink to the bottom". ${ }^{[6]}$ In addition, Dewey proposed that the sports education in schools should not just focus on the theoretical principles but emphasize the extra-curricular sports.

Physical education concept of Tao Xingzhi. (1)Health First. Tao Xingzhi regards a strong physique as the first priority of life. He said physical health is one of the most important life goals." ${ }^{[7]}$ In the discussion of his concept "four questions everyday", he believed that the health is more important than academic achievements, work and virtue and "martial arts" is the best way to cultivate physical fitness. Besides, sports and learning should be moderate, and scientific exercise, diet and appropriate rest are conducive to staying healthy. ${ }^{[8]}$

(2) “Lifetime Sports". The "lifelong sports view" of Tao Xingzhi is contained in his "life education concept", and the key point is the elaboration based on the methodology. He believed that a school is like a sponsored cultural hotel, and people return to life and society eventually. Therefore, only to train the athletic ability of students in school is not conducive to the long-term development of human. ${ }^{[8]}$ Tao Xingzhi pointed out that great contrast inside and outside of school should be avoided and the school education should make students pay much attention to their health when they step into society.

(3)“Little man” teaching. The "little man" method has constructive significance for the school education, especially for schools in areas with critical teacher shortage. He advocated the mutual learning and help in class and after class. He believed that we should spread knowledge to those who have no change to receive education. ${ }^{[9]}$ This is of great significance for students to understand what they have learned.

(4)Teaching, learning and practice in sports. Tao Xingzhi believed that it is necessary to combine teaching, learning and practice. Tao Xingzhi said one starts his life as if he knows just by simply relying on his eyes, but often ends up acquiring nothing. ${ }^{[7]}$ He pointed out that in the process of acquiring a skill, the teaching method should be based on the learning method which should be built on the practice. Then teachers will not overlook the need of students, which otherwise may result in the suffering of teachers and students. To have a picture of the needs of students in their lifetime is conducive to developing the teaching methods, including what to teach and how to each them, and then the training of teachers on this basis is effective and feasible. ${ }^{[10]}$

\section{Comparison of Physical Education Thoughts of Dewey and Tao Xingzhi}

Commonness of Physical Education views between Dewey and Tao Xingzhi and the reason analysis. Both of these two scholars gave special emphasis on the importance of health to personal and social development. Tao believed that physical education could change the outlook of China, 
while Dewey said good cause must be based on a healthy body, if not, he is under the constant threat of diseases and would be too tired of seeing a doctor to do anything else? ${ }^{[4]}$ In the methodology of improving the public health, they both advocate to popularize the practice of sports in the whole society. Once in a lecture in China Dewey proposed that the development of public sports is an effective way to enhance China's national strength, which is a just slightly different expression of Tao's civilian sports. Both of them advocated using the brain smartly to acquire knowledge. Dewey believed that to master skills, reasonability is really indispensable. How can we ensure the rationality of a method without resorting to brain? Tao believed that we should be involved in learning physically and mentally. In addition, both of them proposed that education should be well-around with equal stress on physical education and moral education. Despite without a direct reference to physical education, Tao also advocated that education and practice should be interdependent.

Their commonness is due to the fact that Tao lived in the declined feudal period when education never aroused wide attention. In this case, a large number of students went for further study in United States and Tao was one of them. At Columbia University, Tao chose the courses of Dewey, Kilpatrick, Monroe and other famous educators, but Professor Dewey's lectures and courses have the greatest influence on him.[11]Thus, this gave him an opportunity to meet with his teacher Dewey. Tao has been deeply influenced by Dewey's pragmatism. Dewey has unique insight for pragmatism although he is not the pioneer and has promoted its development. In their views of sports, pragmatism is embodied. Some scholars believe that the educational thought of Tao rooted in the education ideology of his teacher Dewey. In the succession of Dewey, Tao also developed his own education theory according to China's national conditions. [12] This study suggests that their commonness is inseparable with the influence of Dewey's pragmatic philosophy and education thought on Tao in his study at Columbia University. In addition, they all criticized the education in the old days. It is this clear understanding of the drawbacks of traditional education that contributes to their exploration of the deep-level problems of education.

Differences of physical education view between Dewey and Tao and the cause analysis. Differences also exit in their concept of physical education, mainly reflected in the educational media and tasks, as well as the objects and emphasis. Dewey is inclined to the view that sports and games are conducive to the all-around physical and mental development of children and students and help them obtain the necessary experience to adapt to society. Here, games and sports refer to all activities. Tao believes that martial arts are the first choice to enhance people's physique, and his sports mind stresses the role of sports in enhancing the national power. To develop teaching materials, Dewey stresses the importance of students' experience and teaching should be linked to students' life. Tao proposed books with open attitude. What is required of text books is that they must be full of vibrant and applicable ideas. In general, we need life-oriented not text-centered books. ${ }^{[8]}$ In addition, they all pay much attention to practice. The children-centered educational thought of Dewey focuses on students' acquisition of subjective and individual knowledge and skills. Tao's concept, the combination of teaching, learning and practice, gives attention to the equal status of teachers and students in the classroom and proposes that teaching and learning should be based on practice.

The differences are caused by the subjective awareness, for people have different ideas and hobbies, and even they are identical twins. Objectively speaking, Dewey and Tao have social background and are subject to different cultural and educational edification. At that social context, the United States has become a modern power with a leading position in economic development and other aspects in the world. The United States has stepped into an era dominated by cooperation from individualism of early pioneers. ${ }^{[13]}$ China was experiencing the rise and fall, along with backward economic recession and backward thoughts. In the aspect of education, different from the relative popularity of American higher education, only a few of Chinese recognized the importance of advanced education in enhancing the national power, leading to the low level of education. It is not difficult to see that this situation is bound to result in differences in their educational ideology. If Tao just applies the education view of his teacher Dewey's to China directly, things will be bad due 
to different national situation.

\section{Conclusion}

Dewey and Tao Xingzhi are known as world-renowned educators and have a unique opinion for education. Its educational system has also been formed. Admittedly, despite their common stress on physical education, their discussion is quite fragmented. A comparative study of them indicates that they share ideas in emphasis on health and the popularity of sports. The main differences lie in the means and tasks of education. However, their ideas can still apply in modern times, and have some instructive significance for the future development of school sports education in China. What our future work should focus on ensuring their applicability and reasonability in the current situation.

\section{Acknowledgement}

In this paper, the research was sponsored by the humanities special fund of Southwest Petroleum University (Project No. 2015RW015).

\section{References:}

[1]Shao Weide. et al. Influence research on the development of school physical education in China from Dewey's educational theory[J]. Journal of Beijing Sport University.2012 (10):93-96.

[2]Li Tonghui. Tao Xingzhi's outstanding contribution to the modern China's physical quality education [J]. Lantai World. 2013(25):58-59.

[3]Guo Kelei, et al. Comparison between Hu Shi's sports thoughts and Tao Xingzhi's [J]. Sports Culture Guide. 2012(07):132.

[4]Shan Zhonghui\& Wang Fengyu. Dewey’s education speeches in China [M]. Beijing: Education and Science Press.2007:150; 16; 21; 218; 150.

[5] Dewey, J. How are we thinking, experience and education [M]. Beijing: People's Education Press.2005.1:59-60

[6]Dewey, J. School and society, the school of tomorrow [M]. Beijing: People's Education Press. 2005.1: 141.

[7]Tao Xingzhi. Institution of Tao Xingzhi's education thought in Jiangsu province, Tao Xingzhi research institute in Xiaozhuang Normal School , Collection of Tao Xingzhi[M]. Nanjing: Jiangsu People's Education Press.1981:63; 330.

[8]Tao Xingzhi. Tao Xingzhi’s proverbs on education [M]. Harbin press. 2011: 106; 29-10.

[9]Tao Xingzhi. China National Institute for Educational Research. Literary selections of Tao Xingzhi [M].Beijing: Education and Science Press.1981: 129.

[10]Tao Xingzhi, China's educational reform[M]. Anhui: people's publishing house.1981:106.

[11]Zhou Hongyu, Yu Zhixia and XiongXianjun. Tao Xingzhi and Chinese and foreign cultural education [M].People's Education Press,2003: 183.

[12]Zhang jianying. A study on Tao Xingzhi's thought of life education -- a comparison with Dewey's thought on education and life [J]. Hunan Agricultural University. 2010, 06:12.

[13]Jin Linxiang, Tu Tang, et al. A study on Tao Xingzhi in 20th century[M].Shanghai: Shanghai Education Press,2005:202. 